\title{
Intraoperative Neurophysiological Monitoring for Spinal Fusion
}

\section{Monitorização neurofisiológica intraoperatória para fusão espinhal}

\author{
Marco de Agassiz Almeida Vasques ${ }^{1} \quad$ Eliana de Barros Marques Fonseca ${ }^{1}$ \\ ${ }^{1}$ Hospital das Forças Armadas, Brasília, DF, Brazil \\ Address for correspondence Marco de Agassiz Almeida Vasques, MD, \\ Arq Bras Neurocir 2017;36:172-177. \\ PhD, Neurosurgeon, Hospital das Forças Armadas, Brasília, DF, Brazil \\ (e-mail: mvasques.ncr@gmail.com).
}

\author{
Abstract \\ Keywords \\ - intraoperative \\ neurophysiological \\ monitoring \\ - spinal fusion \\ - review
}

The surgical techniques of spinal fusion are frequently used in the treatment of many spine conditions. Apart from having anatomical knowledge, in order to perform those procedures safely, it is essential to utilize all the tools available to assure the appropriate positioning of the materials and avoid neural injury. The goal of this article is to review the literature on the use of intraoperative neurophysiological monitoring for spinal fusion procedures and to discuss the controversies regarding this issue.

As técnicas cirúrgicas de fusão espinhal são frequentemente utilizadas no tratamento de muitas condições da coluna vertebral. Além do conhecimento anatômico, para realizar esses procedimentos com segurança é essencial utilizar todas as ferramentas disponíveis para assegurar o posicionamento adequado dos materiais e evitar lesões neurais. O objetivo deste artigo é revisar a literatura sobre o uso de monitorização neurofisiológica intraoperatória para procedimentos de fusão espinhal e discutir as controvérsias relacionadas a essa questão.

\section{Introduction}

Spinal decompressions and fusions are among the most frequently performed surgeries, ${ }^{1}$ carrying a real chance of neural injury ${ }^{2-5}$ with possibly disastrous consequences for the patients' quality of life and elevated health care costs. ${ }^{6}$ Over the last decade, the use of intraoperative neurophysiological monitoring has become essential in neurosurgical procedures, because it brings safety to the patients, ${ }^{7-10}$ as it can detect impending neurologic compromise, modifying the actions of the operating team to avoid injuries, and it might be considered as a minimal acceptable standard of care for all spinal procedures. ${ }^{11,12}$ The decision of using intraoperative neurophysiological monitoring is still made mostly by the surgeon. ${ }^{13}$
The effectiveness of intraoperative neurophysiological monitoring has been challenged by some studies based on the assumption of a low risk of postoperative deficits and additional costs with small differences in clinical outcomes. ${ }^{14-17}$

In the surgical treatment of spinal pathologies, there are three main goals to achieve: decompression of the neural structures, spinal stability, and preservation of the patient's function. In order to achieve these goals, spine surgeons must have adequate training on the specific surgery and utilize all the tools available to assure the appropriate positioning of the materials and to avoid neural injury. ${ }^{2-5,18}$ Nevertheless, some health insurance companies still insist on denying the coverage for intraoperative neurophysiological monitoring. The main reason for those denials is the financial cost. ${ }^{16,19-21}$ received

March 20, 2017

accepted

May 31, 2017

published online

July 3, 2017
DOI https://doi.org/

10.1055/s-0037-1604135. ISSN 0103-5355.
Copyright $\odot 2017$ by Thieme Revinter

Publicações Ltda, Rio de Janeiro, Brazil
License terms

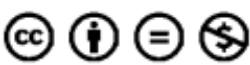


Unfortunately, the economic power of those companies frequently prevails over the medical indications, many times with losses to the patients. A scientific approach, with knowledge of the benefits of the technique, should be used more frequently. In this article, the authors review the literature on the use of intraoperative neurophysiological monitoring for spinal fusion procedures.

\section{Methods}

The Medline/Pubmed database was utilized for the crossed search of articles on the subject with the use of the narrow terms intraoperative neurophysiological monitoring and spinal fusion, with no filters. The LILACS database was also searched, with the use of the narrow term intraoperative neurophysiological monitoring. The resulting articles were analyzed, and their contents were summarized and discussed.

\section{Results and Discussion}

In the literature, there are many publications on the use of intraoperative neurophysiological monitoring (on the PubMed database alone, we found 660 articles with a narrow term research). With more restricted terms, the crossed search using intraoperative neurophysiological monitoring AND spinal fusion resulted in 31 articles. Studying those articles, we found interesting results. From the 31 articles, by applying the article type filtering, there were 9 case reports, ${ }^{22-30} 5$ reviews, ${ }^{28,31-34}$ and 2 clinical trials. ${ }^{11,35}$ Twenty five articles (80.64\%) were published in the period between 2013 and 2017. On the LILACS database, with the use of the narrow term intraoperative neurophysiological monitoring, we found 13 articles, but only 9 were related to spinal surgery. ${ }^{36-44}$

\section{Anterior Fusion}

Legatt et $\mathrm{al}^{22}$ reported a case of anterior cervical discectomy and fusion surgery in which findings on somatosensoryevoked potential monitoring led to the correction of carotid artery compression in a patient with a vascularly isolated hemisphere (no significant collateral blood vessels to the carotid artery territory), and the patient suffered no neurological morbidity. During anterior cervical spine surgery, carotid artery compression by the surgical retractor can cause hemispheric ischemia and infarction in patients with inadequate collateral circulation. Changes in the cortical somatosensory-evoked potentials and no changes in the cervicomedullary somatosensory-evoked potentials warn to the possibility of hemispheric ischemia.

Nair et al $^{30}$ reported a case in which vascular injury was detected by multimodality neurophysiological monitoring during an L3-S1 anterior lumbar interbody fusion, demonstrating the need for multimodality monitoring and the combined use of somatosensory-evoked potentials and motorevoked potentials.

\section{Posterior Fusion}

The importance of intraoperative electromyography monitoring for lumbar fusion was already prospectively evaluated by Welch et al, ${ }^{7}$ once this method early warned the surgeon that redirection of the pedicle probe or screw was necessary to avoid nerve root irritation or injury. Those authors said that stimulus-evoked electromyography proved to be reliable and effective, especially when used in combination with spontaneous electromyography. Once neuroanatomical structures near the bony pedicles of the lumbar spine allow little room for technical error or compromise of the bone during pedicle screw insertion, in these procedures this safety item could be deemed essential.

Kulik et al $^{11}$ performed a computed tomography-based study investigating the relationship between the pedicle screw placement and the stimulation threshold of the compound muscle action potentials measured by intraoperative neurophysiological monitoring. They studied 68 thoracic and 136 lumbar screws placed under electromyography control in 30 patients, and found a more frequent true prediction of the correct position of the screw for lumbar than for thoracic screws. They also concluded that a screw stimulation threshold $>10 \mathrm{~mA}$ does not necessarily indicate correct pedicle screw placement, as there were some false negative cases in which a screw stimulation $>10 \mathrm{~mA}$ without muscle response was associated with misplacement of the screws; a gradual decrease in the screw stimulation thresholds was not observed as the screw placement approached the nerve root; otherwise, a threshold of $2 \mathrm{~mA}$ with muscle response indicates direct contact with nervous tissue. In spite of those limitations, the authors state that "[...]neurophysiological monitoring remains useful and might be regarded as a minimal acceptable standard of care for all spinal procedures except perhaps simple lumbar disc surgery."

Agarwal et $\mathrm{al}^{45}$ performed a retrospective review of 784 patients undergoing posterior spinal fusion with intraoperative neurophysiological monitoring without any baseline deficits. Those authors found somatosensory-evoked potential and motor-evoked potential changes in 3.3\% of the patients undergoing posterior spinal fusion, with the highest incidence at the cervicothoracic level. Eighty-eight percent of the patients with intraoperative neurophysiological monitoring changes had improvements in intraoperative neurophysiological monitoring signals following interventions during surgery. Fifteen percent of the patients had neurological deficits despite surgeon intervention following neurophysiological monitoring alerts.

In scoliosis correction surgeries, as there is a high number of levels, there is a real risk of occurrence of poor positioning of the pedicle screws inserted, even with the aid of intraoperative electromyographic stimulation. ${ }^{36}$ Kobayashi et $\mathrm{al}^{23}$ studied the characteristics of cases with intraoperative transcranial motor-evoked potential waveform deterioration (defined as a decrease in intraoperative amplitude $\geq 70 \%$ of the control waveform) during posterior corrective fusion for adolescent idiopathic scoliosis. Waveform deterioration commonly occurred during rotation maneuvers and more frequently in patients with a larger preoperative Cobb angle. They also found significant relationships between the estimated blood loss and the number of levels fused with waveform deterioration. Rumalla et $\mathrm{al}^{46}$ in a study of trends in spinal fusion surgery 
for pediatric neuromuscular scoliosis, found an increase in intraoperative neurophysiological monitoring from 2009 to 2011. Additionally, in the univariate analysis, they found that the use of intraoperative neurophysiological monitoring was associated with decreased complications and length of stay. Those authors concluded that increasing the use of intraoperative neurophysiological monitoring and posterior-only approaches may combat the high complication rates in neuromuscular scoliosis.

Thirumala et al, ${ }^{31}$ in a review, researched the diagnostic accuracy of somatosensory-evoked potential monitoring during adolescent idiopathic scoliosis fusion. This metaanalysis covering 4,763 operations on idiopathic scoliosis patients showed that the somatosensory-evoked potential is a highly sensitive and specific test, and that iatrogenic spinal cord injury resulting in new neurological deficits was 340 times more likely to present changes in the somatosensoryevoked potential compared with those injuries without any new deficits. Somatosensory-evoked potential monitoring during scoliosis correction surgeries in children remains a highly reliable method for reducing iatrogenic neurologic deficits with high sensitivity and specificity. ${ }^{47}$

Chung et $\mathrm{al}^{24}$ in a technical report, informed that the growing rod technique for spinopelvic dissociation under intraoperative neurophysiological monitoring could be a useful alternative surgical option, especially in patients without neurologic deficit.

Nakamae et $\mathrm{al}^{28}$ described 2 cases of surgical treatment using intraoperative electrophysiological monitoring with transcranial electric motor-evoked potentials and continuous spontaneous electromyography for patients with highgrade dysplastic spondylolisthesis in adolescence. They successfully performed the surgeries without any neurological deficit using intraoperative electrophysiological monitoring.

\section{Lateral Fusion}

Narita et al $^{48}$ studied 36 patients who underwent extreme lateral interbody fusion (XLIF) for lumbar spine degenerative spondylolisthesis or lumbar spine degenerative scoliosis at L4-5 or at a lower level. During the operation, the psoas major muscle was dissected using an index finger fitted with a finger electrode, and the threshold values of the dilator were recorded before and after dissection. The historical controls were 18 patients (who underwent the same procedure for the same indications without the use of the finger electrode). They had no serious neurological complications in any of the patients, but there was a significantly lower incidence of transient neurological symptoms in the finger electrode group (7 [38\%] out of 18 cases versus 5 [14\%] out of 36 cases; $p=0.047$ ). They suggest that this neuromonitoring system using a finger electrode may be useful to prevent XLIF-induced neurological complications.

Grimm et $\mathrm{al}^{49}$ in a retrospective chart review of perioperative complications within the first year after extreme lateral interbody fusion (involving 108 patients), found 25 complications $(23 \%)$ in patients who underwent the procedure. Four patients (3.7\%) experienced major complications, including vertebral body fracture, contralateral nerve root injury, dense quadriceps paresis, and persistent stenosis. There also were minor complications (approach-related thigh pain and/or paresthesias) that were all ultimately resolved. The authors state that dense femoral nerve palsy is a complication that may occur despite intraoperative neurophysiological monitoring.

The femoral nerve preservation in transpsoas lateral access surgery of the spine with the aid of neuromonitoring was addressed by Block et al, ${ }^{33}$ who proposed a theory and technique to utilize motor-evoked potentials to protect the femoral nerve at risk in those procedures. On multiple occasions, their neuromonitoring groups observed significantly degraded amplitudes of the femoral motor- and/or sensory-evoked potentials limited only to the surgical side. Most of these degraded response amplitudes rapidly returned to baseline values with a surgical intervention like the removal of surgical retraction.

Cheng et $\mathrm{al}^{50}$ also debated the requirement for intraoperative neuromonitoring in $90^{\circ}$ lateral transpsoas spine surgery (lateral lumbar interbody fusion). Considering that the lateral approach to the lumbar spine requires passage near or adjacent to the lumbar plexus, the mini-open lateral transpsoas approach uses evoked electromyography integrated into the approach, and instrumentation that stimulates in directional orientations and provides discrete threshold responses to avoid the nerves of the lumbar plexus. Some lateral transpsoas approaches to the lumbar spine have been developed that do not advocate for the use of neuromonitoring, instead relying on direct visualization and avoidance of nerves ("shallow-docking"). They state there is substantially more literature describing the use of neuromonitoring in lateral transpsoas surgery, but reports of direct visualization and avoidance of nerves (shallow-docking) are emergent.

Uribe et $\mathrm{al}^{34}$ reviewed intraoperative electromyography neurophysiological monitoring methods and their application in minimally invasive spine surgery. They state that the use of electromyography during the minimally invasive lateral transpsoas approach to the lumbar spine for interbody fusion contributed to decrease the complication rate from $30 \%$ to less than $1 \%$. The authors consider that in addition to knowledge of the anatomy and image guidance, directional intraoperative electromyography neurophysiological monitoring is crucial to guarantee a safe passage through the psoas muscle during the minimally invasive lateral retroperitoneal approach.

\section{Cost-benefit Issues}

James et $\mathrm{al}^{21}$ investigated the increase in the use of intraoperative neurophysiological monitoring during spine surgery, concluding that as the costs of spine surgeries continue to rise, it becomes necessary to examine and justify the use of different medical technologies, including intraoperative neurophysiological monitoring, during spine surgery. Garces et al, ${ }^{16}$ considering the widespread use of intraoperative monitoring in many types of spinal surgeries, with concerns about its overuse in routine and low-risk procedures, performed a retrospective database review of 112 patients undergoing a 1- or 2-level minimally invasive surgery for transforaminal lumbar interbody fusion. 
They believe that the use of intraoperative monitoring for minimally invasive surgery for transforaminal lumbar interbody fusion provides no added benefit. Ney et $\mathrm{al}^{19}{ }^{19}$ in a large, multiyear, nationally representative dataset, showed that neurophysiological intraoperative monitoring was associated with better clinical outcomes in non-complex spine surgeries (with the largest benefits for laminectomies). The risk of neurologic complications was $75 \%$ higher without the use of neurophysiological intraoperative monitoring. Additionally, the adjusted increase in hospital charges was of only $9 \%$. They also emphasize that the actual cost of neurophysiological intraoperative monitoring is outweighed by a lifetime of lost wages and health care costs from neurologic complications, including spinal cord injury. ${ }^{6,19}$ Husain et $\mathrm{al}^{20}$ comment that this reduction in complications is preferred to the higher-cost issue.

The occurrence of iatrogenic neurologic deficit after lumbar spine surgery (mainly for degenerative spondylolisthesis, spondylosis, scoliosis, and lumbar stenosis) was reviewed by Ghobrial et $\mathrm{al}^{32}$ who worked with a population of 2,783 patients in 12 studies. The authors state that those complications were avoided with the use of neuromonitoring. Thirty patients out of $731(4.1 \%)$ patients had a new onset of a neurologic injury after anterior lumbar interbody fusion or lateral lumbar interbody fusion. Thirty-seven out of 2,052 (1.9\%) patients had a neurologic injury after posterior decompression and fusion. Screw malposition was responsible for 11 deficits. These data show that spinal surgery for lumbar degenerative disease carries a low but real chance of neurologic deficits. Gavrancic et $\mathrm{al}^{51}$ recommend specific tests for the intraoperative neurophysiological monitoring during lumbar spine surgery monitoring. Yaylali et $\mathrm{al}^{52}$ propose the use of intraoperative neurophysiological monitoring also in anterior lumbar interbody fusion.

Eager et $\mathrm{al}^{53}{ }^{53}$ reviewing 2,069 spine cases, found 32 cases with possible intraoperative events. There were 17 cases in which intraoperative neurophysiological monitoring changes affected the course of the surgery and prevented possible postoperative neurological deficits ( 7 due to deformity correction, 5 due to hypotension, 4 due to patient positioning, and 1 due to a screw requiring repositioning), reinforcing the importance of multimodality intraoperative neurophysiological monitoring (including somatosensory-evoked potentials, transcranial electrical motor-evoked potentials, and spontaneous and triggered electromyography) in spinal surgery.

McClendon et $\mathrm{al}^{54}$ studying reoperation patients who received operative correction of proximal junctional kyphosis of the upper thoracic spine, used intraoperative neurophysiological monitoring in all patients.

\section{New Developments}

In a recent study, Turner et $\mathrm{al}^{25}$ evaluated spinal cord perfusion (using a laser Doppler probe fixated to the dura at the level of the pedicle subtraction osteotomy and intrathecal pressure monitoring using a lumbar drain, somatosensoryevoked potential and motor-evoked potential) during adult spinal deformity surgery as a marker for the risk of spinal cord injury. The alterations of perfusion and potentials guided the correction of the deformity. This was direct evidence that fluctuations in spinal cord perfusion may contribute to neurologic changes during adult spinal deformity surgery, contributing to the development of strategies for spinal cord protection during high-risk cases. Eck et $\mathrm{al}^{29}$ reported a case of a patient with an American Spinal Injury Association grade B (ASIA B) spinal cord injury with partially intact baseline intraoperative neurophysiological monitoring who made a complete functional recovery postoperatively, illustrating the potential prognostic value of intraoperative neurophysiological monitoring.

Anesthesia has a fundamental role on intraoperative neurophysiological monitoring, ${ }^{26,27,55}$ as the drugs used may alter the parameters intraoperatively. ${ }^{26}$ There are some options in the choice of anesthesia during intraoperative neurophysiological monitoring, and this choice must consider the specific needs of the procedure (as a more rapid awakening and the feasibility of a rapid wake-up test when irreversible changes in neurophysiological monitoring are noted). ${ }^{27,35}$

The use of different criteria to alarm neurophysiological monitoring during spine surgeries has also been addressed, and the reduction in amplitude potentials (sensitive or motor-evoked potentials) with maximal stimulation for motor-evoked potentials could be a better warning alert than the complete loss of any of these potentials. ${ }^{37}$ The specific needs of the neuromonitoring technique must be discussed with the surgeon in order to obtain the best results possible. There is a type of misplacement of lumbar pedicle screws associated with radicular pain in the standing and seated positions, that may not be detected by conventional monitoring, for example, suggesting the use of systematic pedicle track stimulation prior to the insertion of the lumbar pedicular screw. ${ }^{38}$ Actually, electrical stimulation enables a reduction in the risk of medial positioning, minimizing the use of intraoperative radiographs for thoracic screws. ${ }^{40}$

Concerning pediatric neurosurgical procedures, despite their recent application, neurophysiological monitoring represents an important tool in the prevention and reduction of possible neurological lesions, ${ }^{39,46,56}$ and in some cases it may inform the anatomical site for the corrective surgical maneuver to be performed. ${ }^{57}$

Even in those cases considered simple spine surgeries, the use of intraoperative neurophysiological monitoring has been proved useful, enabling the dynamic neurophysiological diagnosis, the differentiation of the compression at the central or foraminal levels, and the clinical awareness of iatrogenic damage, thereby increasing safety. ${ }^{41}$ Even though intraoperative neurophysiological monitoring does not substitute good surgical technique and care, it is an important tool to provide relevant information to the spine surgeon, and it may provide the best chance to detect and possibly avoid spinal cord and nerve root injuries. ${ }^{58}$ During spine surgery, intraoperative neurophysiological monitoring is, thus, an effective method of monitoring the functional integrity of the spinal cord and nerve roots, reducing risks and improving postoperative results. ${ }^{42-44,59}$ The actual trend is to use multimodal intraoperative neurophysiological monitoring on procedures near or involving neural elements. ${ }^{46,56,58}$ 


\section{Conclusion}

The spine surgery team has the challenge of reconciling the technological developments with the best interest of the health care system and its growing costs. We believe that this reconciliation is feasible to the benefit of the patients health. Based on the literature discussed, multimodal intraoperative neurophysiological monitoring is an extremely useful tool in the prevention of surgery-related neural damages. We can also foresee that the use of this kind of monitoring will be essential in all spine surgical procedures that involve the manipulation of or proximity to nervous structures.

\section{References}

1 Elixhauser A, Andrews RM. Profile of inpatient operating room procedures in US hospitals in 2007. Arch Surg 2010;145(12): 1201-1208

2 Cramer DE, Maher PC, Pettigrew DB, Kuntz C IV. Major neurologic deficit immediately after adult spinal surgery: incidence and etiology over 10 years at a single training institution. J Spinal Disord Tech 2009;22(08):565-570

3 Yadla S, Malone J, Campbell PG, et al. Early complications in spine surgery and relation to preoperative diagnosis: a single-center prospective study. J Neurosurg Spine 2010;13(03):360-366

4 Nasser R, Yadla S, Maltenfort MG, et al. Complications in spine surgery. J Neurosurg Spine 2010;13(02):144-157

5 Campbell PG, Yadla S, Malone J, et al. Complications related to instrumentation in spine surgery: a prospective analysis. Neurosurg Focus 2011;31(04):E10

6 Ney JP, van der Goes DN, Watanabe JH. Cost-benefit analysis: intraoperative neurophysiological monitoring in spinal surgeries. J Clin Neurophysiol 2013;30(03):280-286

7 Welch WC, Rose RD, Balzer JR, Jacobs GB. Evaluation with evoked and spontaneous electromyography during lumbar instrumentation: a prospective study. J Neurosurg 1997;87(03):397-402

8 Bilsky MH. Boachie-Adjei, Shields CB, Baldwin N. Thoracic and lumbar deformities. In: Benzel EC, editor. Spine surgery: techniques, complication avoidance, and management. Philadelphia: Elsevier Churchill Livingstone; 2005:796-823

9 Pahys JM, Guille JT, D’Andrea LP, Samdani AF, Beck J, Betz RR. Neurologic injury in the surgical treatment of idiopathic scoliosis: guidelines for assessment and management. J Am Acad Orthop Surg 2009;17(07):426-434

10 Silva EG, Kojo HD, Joaquim AF, Shaffrey CI. Scoliosis: current overview and treatment considerations. Arq Bras Neurocir 2010;29(04):130-136

11 Kulik G, Pralong E, McManus J, Debatisse D, Schizas C. A CT-based study investigating the relationship between pedicle screw placement and stimulation threshold of compound muscle action potentials measured by intraoperative neurophysiological monitoring. Eur Spine J 2013;22(09):2062-2068

12 Magit DP, Hilibrand AS, Kirk J, et al. Questionnaire study of neuromonitoring availability and usage for spine surgery. J Spinal Disord Tech 2007;20(04):282-289

13 Fehlings MG, Brodke DS, Norvell DC, Dettori JR. The evidence for intraoperative neurophysiological monitoring in spine surgery: does it make a difference? Spine 2010;35(9, Suppl)S37-S46

14 Hamilton DK, Smith JS, Sansur CA, et al; Scoliosis Research Society Morbidity and Mortality Committee. Rates of new neurological deficit associated with spine surgery based on 108,419 procedures: a report of the scoliosis research society morbidity and mortality committee. Spine 2011;36(15):1218-1228
15 Cole T, Veeravagu A, Zhang M, Li A, Ratliff JK. Intraoperative neuromonitoring in single-level spinal procedures: a retrospective propensity score-matched analysis in a national longitudinal database. Spine 2014;39(23):1950-1959

16 Garces J, Berry JF, Valle-Giler EP, Sulaiman WA. Intraoperative neurophysiological monitoring for minimally invasive 1- and 2level transforaminal lumbar interbody fusion: does it improve patient outcome? Ochsner J 2014;14(01):57-61

17 Traynelis VC, Abode-Iyamah KO, Leick KM, Bender SM, Greenlee JD. Cervical decompression and reconstruction without intraoperative neurophysiological monitoring. J Neurosurg Spine 2012; 16(02):107-113

18 Lehman RA, Potter BK, Kuklo TR, et al. Probing for thoracic pedicle screw tract violation(s): is it valid? J Spinal Disord Tech 2004; 17(04):277-283

19 Ney JP, van der Goes DN, Nuwer MR. Does intraoperative neurophysiologic monitoring matter in noncomplex spine surgeries? Neurology 2015;85(24):2151-2158

20 Husain AM. Comment: Neurophysiologic intraoperative monitoring in "low-risk" spine surgeries. Neurology 2015;85(24):2157

21 James WS, Rughani AI, Dumont TM. A socioeconomic analysis of intraoperative neurophysiological monitoring during spine surgery: national use, regional variation, and patient outcomes. Neurosurg Focus 2014;37(05):E10

22 Legatt AD, Laarakker AS, Nakhla JP, Nasser R, Altschul DJ. Somatosensory evoked potential monitoring detection of carotid compression during ACDF surgery in a patient with a vascularly isolated hemisphere. J Neurosurg Spine 2016;25(05):566-571

23 Kobayashi K, Imagama S, Ito Z, et al. Transcranial motor evoked potential waveform changes in corrective fusion for adolescent idiopathic scoliosis. J Neurosurg Pediatr 2017;19(01):108-115

24 Chung HY, Suk KS, Lee HM, et al. Growing rod technique for the treatment of the traumatic spinopelvic dissociation: a technical trick. Spine J 2016;16(03):e209-e214

25 Turner JD, Eastlack RK, Mirzadeh Z, Nguyen S, Pawelek J, Mundis GM Jr. Fluctuations in Spinal Cord Perfusion During Adult Spinal Deformity Correction Identify Neurologic Changes: Proof of Concept. World Neurosurg 2016;85:365.e1-365.e6

26 Allison DW, Gertsch JH, Mahan MA, Sheean GL, Brown JM. Anesthesia considerations for monitoring TCMEPs in adults diagnosed with poliomyelitis as children: a case report. Neurodiagn J 2014;54(01):28-35

27 Sloan TB, Vasquez J, Burger E. Methohexital in total intravenous anesthesia during intraoperative neurophysiological monitoring. J Clin Monit Comput 2013;27(06):697-702

28 Nakamae T, Tanaka N, Nakanishi K, et al. Surgical treatment of highgrade dysplastic spondylolisthesis using intraoperative electrophysiological monitoring: report of two cases and review of the literature. Eur J Orthop Surg Traumatol 2013;23(Suppl 1):S121-S127

29 Eck JC, Martin CJ, Lapinsky A, Connolly PJ, Dipaola C. Does intraoperative neurophysiological monitoring have predictive value for functional recovery following spinal cord injury? A case report. J Clin Monit Comput 2013;27(01):93-96

30 Nair MN, Ramakrishna R, Slimp J, Kinney G, Chesnut RM. Left iliac artery injury during anterior lumbar spine surgery diagnosed by intraoperative neurophysiological monitoring. Eur Spine J 2010; 19(Suppl 2):S203-S205

31 Thirumala PD, Cheng HL, Loke YK, Kojo Hamilton D, Balzer J, Crammond DJ. Diagnostic accuracy of somatosensory evoked potential monitoring during scoliosis fusion. J Clin Neurosci 2016;30:8-14

32 Ghobrial GM, Williams KA Jr, Arnold P, Fehlings M, Harrop JS. Iatrogenic neurologic deficit after lumbar spine surgery: A review. Clin Neurol Neurosurg 2015;139:76-80

33 Block J, Silverstein JW, Ball HT, et al. Motor evoked potentials for femoral nerve protection in transpsoas lateral access surgery of the spine. Neurodiagn J 2015;55(01):36-45 
34 Uribe JS, Vale FL, Dakwar E. Electromyographic monitoring and its anatomical implications in minimally invasive spine surgery. Spine 2010;35(26, Suppl)S368-S374

35 Martin DP, Bhalla T, Thung A, et al. A preliminary study of volatile agents or total intravenous anesthesia for neurophysiological monitoring during posterior spinal fusion in adolescents with idiopathic scoliosis. Spine 2014;39(22):E1318-E1324

36 Gavassi BM, Oliveira CEAS, Barsotti CEG, Santos FPE, Pratali RR, Ferreira RJR. Positioning of pedicle screws in adolescent idiopathic scoliosis using electromyography. Coluna/Columna 2015; 14(02):100

37 Dominici M, Comerlato EA, Ventura FD, Chaloult E. Accuracy of two different criteria for neurophysiological intraoperative monitoring (NIOM) in spine/spinal cord surgeries. Arq Bras Neurocir 2014;33(01):1-5

38 González VG, Burgos-Flores J, Del-Olmo T, et al. Misplacement of lumbar pedicular screws that produce postoperative mechanical radiculalgia with normal intraoperative neurophysiological stimulation: the value of neurophysiological stimulation at the pedicular mid-track. Coluna/Columna 2013;12(04):322-325

39 Habeych S, Miguel E. Intraoperative neurophysiological monitoring in pediatrics: Current controversies. . Salud UIS 2012;44(01):7-16

40 García PC, Pérez MH, Lorensu PP, Rodríguez BD, Hernández PS, Rodrigo AA. Predictive value of electrical stimulation in cases of malposition of thoracic pedicle screws in spine surgery. Columna 2012;11(02):169-170

41 Rodrigues LMR, Rosa FW, Ferreira RJ, Ueno F, Milani C. Herniated lumbar disc surgery in triathlon athletes with intraoperative neurophysiologic monitoring. Einstein (Sao Paulo) 2011;9(04):530-533

42 Kai MR, Brooks JBB, Silva CAC, Rotta JM, Botelho R. The value of multimodal intraoperative monitoring during spinal surgery. Arq Bras Neurocir 2011;30(01):3-6

43 Pasqualini W, Carvalho MOP, Kanno RM, Castellon AT, Tebet MA. Intraoperative neurophysiological monitoring of patients undergoing idiopathic scoliosis surgical correction. Coluna/Columna 2010;9(03):282-286

44 Collado-Corona MA, de Leo-Vargas R, Sandoval-Sánchez V, DíazHernández A, Gutiérrez-Sougarret BJ, Shkurovich-Bialik P. Neurophysiological monitoring in spinal cord surgery. Cir Cir 2009;77 (05):385-390

45 Agarwal N, Hamilton DK, Ozpinar A, Choi P, Hart R, Yaylali I. Intraoperative Neurophysiologic Monitoring for Adult Patients Undergoing Posterior Spinal Fusion. World Neurosurg 2017;99:267-274

46 Rumalla K, Yarbrough CK, Pugely AJ, Koester L, Dorward IG. Spinal fusion for pediatric neuromuscular scoliosis: national trends, complications, and in-hospital outcomes. J Neurosurg Spine 2016;25(04):500-508
47 Thirumala PD, Bodily L, Tint D, et al. Somatosensory-evoked potential monitoring during instrumented scoliosis corrective procedures: validity revisited. Spine J 2014;14(08):1572-1580

48 Narita W, Takatori R, Arai Y, et al. Prevention of neurological complications using a neural monitoring system with a finger electrode in the extreme lateral interbody fusion approach. J Neurosurg Spine 2016;25(04):456-463

49 Grimm BD, Leas DP, Poletti SC, Johnson DR II. Postoperative Complications Within the First Year After Extreme Lateral Interbody Fusion: Experience of the First 108 Patients. Clin Spine Surg 2016;29(03):E151-E156

50 Cheng I, Acosta F, Chang K, Pham M. Point-Counterpoint: The Use of Neuromonitoring in Lateral Transpsoas Surgery. Spine 2016; 41(Suppl 8):S145-S151

51 Gavrancic B, Lolis A, Beric A. Train-of-four test in intraoperative neurophysiologic monitoring: differences between hand and foot train-of-four. J Clin Neurophysiol 2014;31(06):575-579

52 Yaylali I, Ju H, Yoo J, Ching A, Hart R. Intraoperative neurophysiological monitoring in anterior lumbar interbody fusion surgery. J Clin Neurophysiol 2014;31(04):352-355

53 Eager M, Shimer A, Jahangiri FR, Shen F, Arlet V. Intraoperative neurophysiological monitoring (IONM): lessons learned from 32 case events in 2069 spine cases. Am J Electroneurodiagn Technol 2011;51(04):247-263

54 McClendon JJr, O'Shaughnessy BA, Sugrue PA, et al. Techniques for operative correction of proximal junctional kyphosis of the upper thoracic spine. Spine 2012;37(04):292-303

55 Subramanian A, Wanta BT, Fogelson JL, Curry TB, Hannon JD. Time to extubation during propofol anesthesia for spine surgery with sufentanil compared with fentanyl: a retrospective cohort study. Spine 2014;39(21):1758-1764

56 Şenköylü A, Zinnuroğlu M, Börçek A, Aktaş E, Güngör İ, Beyazova M. Comparison of multimodal intraoperative neurophysiological monitoring efficacy in early childhood and school aged children undergoing spinal surgery. Acta Orthop Traumatol Turc 2017; 51(01):49-53

57 Gavaret M, Pesenti S, Diop-Sene MS, Choufani E, Bollini G, Jouve JL. Intraoperative spinal cord monitoring: Lesional level diagnosis. Orthop Traumatol Surg Res 2017;103(01):33-38

58 Chen Y, Wang BP, Yang J, Deng Y. Neurophysiological monitoring of lumbar spinal nerve roots: A case report of postoperative deficit and literature review. Int J Surg Case Rep 2017;30:218-221

59 Schär RT, Sutter M, Mannion AF, et al. Outcome of L5 radiculopathy after reduction and instrumented transforaminal lumbar interbody fusion of high-grade L5-S1 isthmic spondylolisthesis and the role of intraoperative neurophysiological monitoring. Eur Spine J 2017;26(03):679-690 